\section{Las epidemias de cólera en Córdoba a través del periodismo: la oferta de productos preservativos $y$ curativos durante la epidemia de 1867-1868*}

\section{Cholera epidemics in Córdoba as seen} through the press. The supply of preventive and curative products during the 1867-68 epidemic

\section{Adrián Carbonetti}

Director del equipo de investigación y docente de la Escuela de Historia de la Facultad de Filosofía y Humanidades y del Centro de Estudios Avanzados de la UNC, Investigador Adjunto Conicet Rómulo Carbia 2771 Bo Poeta Lugones Cordoba - Argentina acarbonetti@cea.unc.edu.ar

María Laura Rodríguez

Licenciada en Historia y alumna del Doctorado en Ciencias Políticas del Centro de Estudios

Avanzados de la UNC, Becaria Conicet Lisandro de la Torre 1832 Depto. 7, San Vicente Córdoba - Argentina

\section{Colaboradores:}

Noelia Rimonda

Yamila Martina

Estudiantes de Historia. Escuela de Historia de la Facultad de Filosofía y Humanidades de la UNC
CARBONETTI, Adrián; RODRÍGUEZ,

María Laura; RIMONDA, Noelia; MARTINA, Camila. Las epidemias de cólera en Córdoba a través del periodismo: la oferta de productos preservativos y curativos durante la epidemia de 1867-1868. História, Ciencias, Saúde Manguinhos, Rio de Janeiro, v.14, n.2, p.405-419, abr.-jun. 2007.

La enfermedad es un momento de crisis tanto individual como social. La cercanía de la muerte debido a la dolencia genera en las sociedades estrategias para evadirla o curarla. Las epidemias y especialmente las de cólera tuvieron una impronta muy fuerte en la sociedad argentina y especialmente en la cordobesa ya que la primera de ellas fue devastadora en términos demográficos y sociales. En este artículo pretendemos analizar el ofrecimiento de productos, que se publicaba en la prensa escrita en la primer epidemia del año 1867/68. Partimos de la hipótesis de que los productos que se ofrecían desarrollaban un comercio de carácter suntuario que no eran objeto de transacciones comerciales habitualmente por la población en momentos no epidémicos y que a su vez estaban dirigidos hacia los sectores de mayor nivel adquisitivo.

PALABRAS CLAVES: epidemia; cólera; Córdoba; publicidad; prensa escrita.

CARBONETTI, Adrián; RODRÍGUEZ, María Laura; RIMONDA, Noelia; MARTINA,Camila.

Cholera epidemics in Córdoba as seen through the press. The supply of preventive and curative products during the 1867-68 epidemic. História, Ciencias, Saúde Manguinhos, v.14, n.2, p.405-419, April-June 2007.

Throughout human history, disease has always represented a moment of crisis for individuals and societies. When death brought by disease hangs heavy over societies, they are led to develop strategies to prevent and cure it. Epidemics, especially cholera epidemics, have had a strong impact on Argentine society and especially on Córdoba residents, because the first cholera outbreak was demographically and socially highly devastating. In this article we analyze the supply of products advertised in the press (the only media available at the time) during the first epidemic, which broke out in 1867-8. Our hypothesis is that the products available, which we believe were consumed by some groups in society, led to a sumptuary trade that was not common among the population when there were no epidemics. At times of epidemics, these products were directed towards more affluent groups. We also believe that the supply of such products changed as their trade increased.

KEYWORDS: epidemic; cholera; Córdoba; advertising; press. 
${ }^{*}$ Este trabajo es parte de uno mayor que pretende analizar el impacto social de las epidemias de cólera en la ciudad de Córdoba, República Argentina.
Crotoxina en la década de 1990, gorgojos de arroz en el siglo XXI, ambos debían consumirse para curar el cáncer, vacunas Pueyo, Friedman, tratamientos 'Azuero' y 'Zequeira' para la tuberculosis, pastillas de alcanfor para evitar la poliomielitis. En todo momento y frente a la dolencia y la muerte las sociedades tienden a buscar y consumir, con la anuencia de la medicina o sin ella, productos para combatir o prevenir la enfermedad. En incontables momentos, especialmente frente a las epidemias, aparecían prácticas de todo tipo para evadir un destino que parecía inevitable. En este trabajo pretendemos estudiar algunas de esas prácticas.

La enfermedad y la salud constituyeron una parte importante de las preocupaciones de las sociedades, especialmente las dolencias infectocontagiosas que en sus formas epidémicas generaban una alta mortalidad (Mc Neill, 1984). Estas dolencias aparecieron cuando la humanidad comenzó a agruparse en ciudades lo que provocó que se extendiera la cadena de contagios (McKeown, 1990). La viruela, el sarampión, la gripe, el tifus, la fiebre amarilla, fueron los males más comunes a los cuales se agregaron la peste bubónica, que devastó el continente europeo durante el siglo XIV y a su vez fuera causa y consecuencia de carestías y crisis económicas y sociales (Ruggiero, Tenenti, 1970), y el cólera que, transformado en pandemia a principios del siglo XIX, comenzó una presencia mundial que se extendió hasta fines del siglo XX.

La incidencia de estas enfermedades sobre la población, las consecuencias económicas de interrupción del comercio, el abandono de los campos y la ciudad y el impacto sobre las sociedades llevaron a los poderes públicos, a fines de la Edad Media y principios de la Moderna, cuando comenzaban a desarrollarse incipientes formas capitalistas, a conformar sistemas de salud que trataran de evitar este tipo de enfermedades y lucharan contra ellas cuando aparecían (Nadal, 1992; Cipolla, 1993).

No obstante que los poderes públicos empezaron su actuación para prevenir y luchar contra los azotes epidémicos, las reacciones sociales continuaron siendo similares a las de la Edad Media: huida por parte de los más acaudalados; realización de procesiones para apaciguar la 'ira' de Dios, ya que se creía que éstas eran parte de un castigo divino, y luego la consumición de algún tipo de producto que, por razones nunca explicadas, podían preservar de la enfermedad. Estas reacciones recorren prácticamente toda la historia de los azotes epidémicos hasta bien entrado el siglo XX.

Estas prácticas pueden ser divididas en dos categorías: aquellas que tenían un carácter social, es decir que estaban destinadas a salvar a la población en su conjunto y aquellas de carácter individual que tendían a salvar a quien las llevaba a cabo o las consumía. Dentro de las primeras podemos apreciar las procesiones; dentro de las segundas, las huidas y la consumición de productos ' preser- 
vativos' o 'curativos'. En este trabajo pondremos el acento en las prácticas de carácter individual y especialmente en el ofrecimiento de ciertos productos por parte de médicos, almacenes, farmacias para preservar del terrible cólera a aquellos que los consumieran, tomando como caso la epidemia de cólera en la ciudad de Córdoba (1867-1868).

Partimos de la hipótesis de que los productos que se ofrecían y que eran consumidos por algunos sectores de la sociedad desarrollaban un comercio de carácter suntuario, que no eran habitualmente objeto de transacciones comerciales por la población en momentos no epidémicos y que a su vez estaban dirigidos hacia los sectores de mayor nivel adquisitivo. En este sentido se puede apreciar que los sectores sociales de mayores recursos podían optar por una serie de estrategias más contundentes para evitar el sufrimiento y muerte provocados por la enfermedad que aquellos sectores que contaban con escasos recursos.

\section{Características del cólera}

Durante la conformación de la economía del mundo, las epidemias y enfermedades endémicas de carácter contagioso, pero especialmente las primeras, continuaron generando una importante cantidad de muertes en la población europea y a partir del siglo XVI en las poblaciones americanas. Es que éstas estaban íntimamente relacionadas a las condiciones de vida de la población, a los flujos económicos y a las guerras (Nadal, 1992). A pesar de los importantes avances que se produjeron en la medicina y en la salud pública en los siglos XVIII y XIX, las condiciones de vida del proletariado que generaba la revolución industrial, especialmente en Inglaterra, impactaron sobre el desarrollo de enfermedades infectocontagiosas aumentando el número de casos de muerte por tuberculosis, gastroenteritis, fiebre amarilla, cólera.

En este contexto es que se debe estudiar la problemática del cólera. Su salida de la India y desarrollo en todo el mundo está relacionado al crecimiento del capitalismo en su etapa de expansión colonial. No es una casualidad que sea justamente en el siglo XIX que se desarrolla en forma pavorosa y, como dice Mc. Neill (1984, p.20), "el antiguo y consolidado sistema de difusión del cólera por el territorio indio se cruzó ahora con el nuevo sistema de comercio y los movimientos militares impuestos por los británicos. El resultado fue que el cólera sobrepasó sus límites habituales y floreció en territorios nuevos e inhabituales, totalmente carentes de la resistencia y de las reacciones acostumbradas a su presencia". A su vez, las condiciones materiales de vida que genera justamente este sistema, con carencias de carácter higiénico de grandes sectores de la población, escasa atención médica, medidas sanitarias paupérri- 
1 Para el caso europeo son innumerables los trabajos acerca de esta enfermedad en casi todos los países pero son de destacar los trabajos de Bourdelais y Raulot (1987) y los trabajos en Peurs et terreurs face a la contagion (Bardet et al., 1988). Para el caso español son varios los trabajos desarrollados a lo largo de la década de 1990: Betancor Gómez, Marset Campos, 1994;

Fernández Sanz, 1991 y Gómez Días, 1993.

2 Para el caso de la ciudad de Rosario, el trabajo de Agustina Prieto, 1996; para el caso de la ciudad de Córdoba, Arcondo, 1997. Para el caso tucumano, Goldman, 1990. Para el caso de la provincia de Buenos Aires, Tancredi y Tuis, 2001. mas frente a una crisis sanitaria, permiten su crecimiento en la mayoría de los países europeos y luego americanos. ${ }^{1}$

En la Argentina se dieron, durante la segunda mitad del siglo XIX, tres epidemias de cólera: 1867, 1868, 1871. La ocurrida en 18861887 y la de 1894 dejaron, indudablemente, una impronta en la sociedad desde la perspectiva de su impacto sobre la dinámica de la población en algunas regiones, generando impotencia en la ciencia médica y en el Estado, imponiendo el terror en sociedades indefensas que recurrieron a todo tipo de prácticas y generando políticas destinadas a evitar la repetición del desarrollo de esta enfermedad.

El cólera incidió de forma distinta en los diferentes azotes epidémicos sobre las ciudades argentinas, así en la ciudad de Córdoba en la epidemia de 1867/1868 durante el período que duró la enfermedad se enterraron 2.371 personas, en su mayoría por el cólera. Esta cifra representa aproximadamente $8 \%$ de su población. En Rosario, en 1886/1887, morían 1.256 personas lo que representó aproximadamente el 2,5\% de la población (Pietro, 1996, p.61). En Tucumán, la epidemia de 1886/1887 provocaba 1.887 defunciones, representando el 4,7\% de muertes sobre el total de la población.

El incipiente campo de la historia de la salud y la enfermedad en la Argentina se ha ocupado poco del desarrollo de las epidemias de cólera en el país. ${ }^{2}$ Estos trabajos han hecho hincapié en problemáticas referidas a la actuación que le cupo al Estado, la relación entre medio ambiente y enfermedad, las reacciones sociales frente a la epidemia y las acciones que se tomaron para combatirla. Sin embargo, no se han enfrascado en los medios, productos y prácticas utilizados por la población para evitar la epidemia tanto desde el punto de vista social como individual.

Partimos del concepto de enfermedad de Jean Charles Sournia, por el cual la enfermedad no tiene existencia en sí, es una entidad abstracta a la cual el hombre le da un nombre. Esa concepción de la enfermedad depende del desarrollo del conocimiento médico y resulta de la sociedad que circunda la ciencia médica: "los médicos ... participan de sus ideas, de sus fantasmas, de sus resistencias a los cambios y de su encerramiento en modelos de conocimiento sobre la organización del mundo y de los mecanismos de la vida" (Sournia, 1997, p.360)

Al momento de iniciarse la primera epidemia de cólera en Argentina, los paradigmas que determinaban el accionar de la medicina eran fundamentalmente la teoría miasmática que postulaba que la enfermedad se producía como consecuencia de los miasmas (olores nauseabundos) que llevaban partículas que al ingresar en el cuerpo humano provocaban la enfermedad y la teoría del 'contagio' que tenía como premisa que la dolencia se producía como consecuencia del contacto de una persona enferma con una sana (Carbonetti, 2003). Estas teorías que en sus explicaciones, muchas veces se encon- 
${ }^{3}$ En el Eco de Córdoba, el 29 de marzo de 1867, aparece una nota titulada "El cólera en Rosario", donde una carta particular denunciaría la existencia de una enfermedad cuyos síntomas serían los mismos que el cólera morbus, pero los médicos no se pueden poner de acuerdo; unos dicen que es colerina femenina y otros colerina masculina. El 3 de abril, este mismo periódico, transcribía un artículo tomado del Siglo, diario montevideano, donde se negaba la transportación de un punto a otro del cólera y por lo tanto de su contagio. traban más cerca de la magia que de la medicina científica, determinaban también las prácticas sociales a la hora de evitar la enfermedad.

Hacia 1867, el cólera había invadido las ciudades de Buenos Aires, Rosario, Corrientes, Entre Ríos y golpeaba también a las tropas del Ejército instalado en el Nordeste argentino como consecuencia de la guerra con el Paraguay, tardando unos meses más en llegar a la provincia de Córdoba. Si bien el cólera azotaba otras provincias, la población y el Estado cordobés habían tomado algunas precauciones. No obstante previsiones (se había instalado un lazareto de observación en Río Segundo), en diciembre de 1867, el cólera hacía su ingreso en territorio de la provincia de Córdoba: el 6 de diciembre se daban algunos casos en el pueblo de Villa Nueva y Villa María y el 16 de diciembre invadía la ciudad de Córdoba (Penna, 1897).

\section{Algunos productos para prevenir el cólera}

El desarrollo de la enfermedad en toda la zona del litoral argentino y en el escenario de la guerra con el Paraguay, en coincidencia con brotes en Brasil y Uruguay durante el año 1867, generó en la población de la ciudad un fuerte temor. Se trataba de una dolencia poco conocida, extraña, que producía síntomas espectaculares antes de la muerte y sobre la cual los médicos no llegaban a un acuerdo sobre su propagación, origen y letalidad. ${ }^{3}$

Frente a estos temores comenzaron a aparecer en el único periódico de Córdoba recetas y artículos que estaban destinados a la prevención del mal. Muchos de estos productos, en la mayoría de los casos pócimas, estaban en relación a las nociones acerca de las formas en que se transmitía la enfermedad y que circulaban en la cultura popular. Un ejemplo de ello es el remedio casero que publicaba el Eco de Córdoba en su edición del 6 de abril. En esa nota, el periódico refería que se trataba de una receta de carácter casero que estaba destinado a curar "cólico miserere, colerina etc.":

Cuando se siente vahídos, flojedad en las piernas, síntomas de indigestión o cualquier otra enfermedad del género debe meterse al enfermo en la cama y conservar abrigo y tomar con frecuencia té de manzanilla lo más fresco posible. Cuando es sólo atacado por el estómago o vientre basta con té o infusión fuerte de musgo perlado legítimo. (Eco..., 6 abr. 1867)

Según relataba el artículo en el final, este remedio se había probado con éxito para combatir al cólera en Montevideo, Rosario y San Nicolás. Las pociones eran comunes en la era pre microbiana pues la creencia del origen común de las dolencias llevaba a utilizar, también, remedios similares para todo tipo de enfermedades. 
Unos días después, el 16 de abril de 1867, el Eco de Córdoba, transcribía una nueva receta para combatir el cólera, esta vez la fórmula estaba compuesta por algunos compuestos químicos:

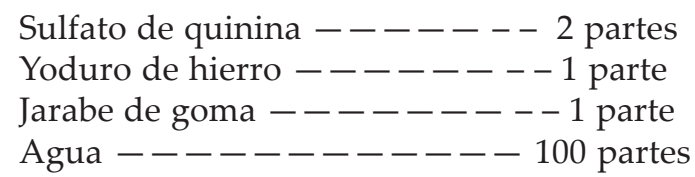

El remedio mencionado era combinado con compresas de hielo y agua fría. La noticia ponía el acento en la utilización por parte de médicos franceses obteniendo "grandes resultados". La química, una de las disciplinas que en Occidente había tenido un fuerte desarrollo a partir del siglo XVIII, tenía una fuerte presencia en la farmacopea, especialmente médica y en menor medida en la popular. Sin embargo, aparecían medidas escasamente entendibles y poco exactas en el modo de aplicación en la pócima que se pretendía aplicar. No sabemos si este tipo de remedios se utilizó masivamente en la cura y prevención del cólera, de todos modos generaba la oferta de nuevos productos que en momentos no epidémicos eran escasamente utilizados.

Una oferta distinta, esta vez para prevenir el cólera, surgía en el periódico el Eco de Córdoba en 18 de abril de 1867: se trataba de cigarrillos destinados a hombres en edad adulta, jóvenes, tal vez los únicos con mandato social para la utilización del cigarrillo.

La nota titulada "Cigarrillos contra el cólera" expresaba una publicidad destinada a un público joven y con un lenguaje jocoso: "No hay mozalbete que ahora no use cigarrillos a la Raspaill contra el cólera. Ello es que el Sr. Mayuard se ha hecho de celebridad con la preparación de cigarrillos y que tendrá pedido exorbitante. Con que caballeritos de la buena facha que no llevéis antídoto, proveeos de él" (Eco..., 18 abr. 1867).

Si bien la publicidad no expresaba la forma de actuación del cigarrillo como producto preventivo contra el cólera, su propiedad estaba implícita. Existía, hacía tiempo, la percepción de que la enfermedad se contagiaba a través de los miasmas, pequeñas partículas que surgiendo de lugares malolientes se introducían en el cuerpo humano generando la enfermedad. El cigarrillo actuaba, de esta forma, como preventivo frente a las partículas malolientes. El olor que producía el cigarrillo pretendía evitar los hedores que pudieran producir la enfermedad. En el mismo sentido eran utilizados el alcanfor y la misma lavandina, esta última para limpiar los deshechos de los enfermos.

El 30 de abril, nuevamente en el Eco de Córdoba, aparecía una publicidad de la casa Carlos Barrevier, del centro de la ciudad, donde se ofrecía una serie de artículos que actuarían como preservativos contra el cólera. Esta vez se trataba de artículos suntuarios 
que contenían fundamentalmente alcohol, posiblemente en relación a la percepción de que el cólera al igual que otras enfermedades se presentaba como consecuencia de un enfriamiento del organismo (Carbonetti, 2003, P.151).

Preservativos contra el cólera

Cognac Legítimo Blanco (artículos exclusivos)

Cognac marca United Growers

Vino de Burdeos en damajuana

Vino fino en $1 / 2$ botella

Jerez en $1 / 2$ botella

Cigarrillos, habanos

Vinos de Champagne, rosados, finos

Chocolate Vainilla

(Eco..., 23 abr. 1867)

El ofrecimiento de estos artículos, en muchos casos, entraba en contradicción con los consejos en referencia a las comidas que la municipalidad publicaba en el diario antes mencionado como prevención para no contraer el cólera y que eran elaborados por el médico de la ciudad. En esa publicación se aconsejaba comer "frugalmente y en preferencia las carnes frescas, los huevos pasados por agua y blandos, el pan, caldo, café y vino". Esta alimentación favorecería la digestión y por lo tanto permitiría evadir el cólera, que al ser una enfermedad del aparato digestivo estaba relacionada con la digestión de los alimentos. De ahí que dentro de los productos prohibidos se encontraban los "licores espirituosos y todo alimento que exija una digestión laboriosa" (Eco..., 14 abr. 1867). Las recomendaciones antes mencionadas se relacionaban a su vez con los excesos de todo tipo (bebidas, comidas y sexo), otra creencia del momento que llevaba a la enfermedad y que en muchos casos era tomada por los médicos de la ciudad como cierta: "Los ebrios, los gastrónomos y los libertinos han sido siempre los predilectos de estas enfermedades" (Eco..., 14 abr. 1867).

A pesar de que el cólera no alcanzó a llegar a la ciudad de Córdoba, durante los meses de mayo, junio y julio los avisos referidos a las pociones y estrategias para evitar el cólera continuaron apareciendo en el periódico.

\section{El cólera y la publicidad}

La enfermedad no sólo era un factor importante en el desarrollo de la oferta y demanda de productos en muchos casos suntuarios y que es posible no hayan tenido en momentos no epidémicos una demanda muy activa; también servía para centralizar la atención de los lectores del periódico. Así, el 30 de abril de 1867 aparecía un aviso con el título "El cólera en Córdoba". Sin embargo, cuando se 
leía dicho apartado se refería a la pérdida de un aro con incrustación de topacio que se le había perdido a una señora de la ciudad y al pedido de ésta para que fuera devuelto en su casa (Eco..., 30 abr. 1867). La misma estrategia para llamar la atención del lector se utilizaba en otros rubros: El 5 de julio de 1867 nuevamente aparecía un aviso con el título: "El cólera ha llegado" pero la lectura del apartado permitía saber la puesta en venta de una casa en la ciudad de Córdoba (Eco..., 5 jul. 1867).

Con la finalización de la epidemia en Rosario, el cólera dejó de ser una amenaza para la población cordobesa y por lo tanto un elemento que no generaba la atención de lectores y tampoco era un factor de consumo de artículos que supuestamente deberían impedir su propagación. Por lo tanto, los anuncios de todo tipo desparecieron del periódico analizado.

\section{La aparición de la epidemia y el desarrollo de la compraventa de productos}

A mediados de diciembre de 1867 nuevamente el cólera amenazaba a la ciudad de Córdoba, según el Eco de Córdoba. En Villa Nueva, un pueblo a 150 kilómetros de la ciudad, se habían producido tres casos. El 12 del mismo mes, el municipio acordaba algunas medidas higiénicas: éstas se basaban fundamentalmente en proveer de cal que mezclada con agua debería regarse por las habitaciones y letrinas.

El día 12 ordenaba el cierre de las diligencias y carruajes provenientes de Villa Nueva: "Suspensión del trabajo en barrancas y curtiembres, prohibiendo la venta de frutas que no estén maduras, cubrir con cal los cajones de muertos y fumigar la correspondencia" (Eco..., 12 dic. 1867).

El día 13 se publicaban nuevamente 'las medidas preventivas'. Entre muchas se encontraban: levantarse media hora antes de que saliera el sol, pasearse al aire libre, ventilar habitaciones y camas, sahumar las habitaciones con "romero, alucema y benjuí", comer con moderación, beber vino en las comidas, con moderación y que sea más bien alcohólico, no agrio, evitar las reuniones numerosas, conservar el ánimo sereno, hacer ejercicios, no tener miedo y no tomar mate. Los sacerdotes deberían prohibir el ayuno y las penas corporales (Eco..., 13 dic. 1867).

Como se puede apreciar, en los consejos que se exponían en el periódico había una serie de medidas que estaban acordes a las miradas médico-sociales de la época. El temor a los miasmas se puede apreciar en los consejos de sahumar y ventilar las habitaciones, evitar las reuniones numerosas estaba destinado a evitar el contagio, pero además había otra percepción: de que las condiciones psicológicas del individuo facilitaban el desarrollo de la enfermedad. 
Según el médico de la ciudad, el andamiaje de la farmacopea, en caso de que la enfermedad se produjera, era el siguiente: "Al sentir los síntomas se toma té de manzanilla con azúcar y 13 a 20 gotas de espíritu anti-colérico concentrado y frotaciones en todo el cuerpo." Eso era todo lo que recomendaba el médico de la ciudad frente al cólera.

El 14 de diciembre, la farmacia Agaita exponía en un aviso en el Eco de Córdoba que en su local se vendía un licor anticolérico, mientras que la farmacia el Águila vendería las frotaciones anticólera. En la misma botica se vendería el cloruro de cal y Labarraque.

El 16 de diciembre se detectaban los primeros casos de cólera en la ciudad (Penna, 1897, p.160) y el día 19 aparecía una publicidad sobre una poción denominada "espíritu anticolérico". Este producto se expedía en la droguería el Ancla Dorada. En la publicidad se señalaba que el licor había sido usado en Europa y Buenos Aires y que había sido recomendado por la revista médica de París y por el consejo de higiene de Buenos Aires e incluso había sido aprobado por el médico de la ciudad (Eco..., 19 dic. 1867). Salvo lo expuesto en la publicidad, no aparecía aprobación oficial por parte del médico de la ciudad respecto a la venta y consumición de este producto. La publicidad terminaba con el anuncio de que a aquellos que comprobaran ser pobres de solemnidad se les despacharía gratis.

Eran momentos de fuerte crecimiento de casos de cólera y comenzaron a surgir en mayor número avisos en los cuales los productos que se publicitaban se destacaban por poseer propiedades para salvar a quien lo consumiese del flagelo. En el mismo momento en que aparecía la publicidad sobre el cólera relatada en el párrafo anterior, el Eco de Córdoba emitía otra publicidad. Al igual que en el caso anterior, se trataba de un licor: "Licor de ginebra, remedio legítimo para todas las enfermedades y principalmente para el cólera y fiebre amarilla. Únicos fabricantes Juan Peters en Hamburgo." El frasco de dicho licor, marca Virgen del Carmen, se vendía a 12 reales en dos casas: Senestrari Hnos. y en la Confitería de Buenos Aires, al frente de la casa principal.

El cólera no solo generaba una nutrida cantidad de productos destinados a preservar y curar la enfermedad, también una competencia entre diferentes negocios que ofrecían productos eficaces para evadir la enfermedad y a distintos precios. Este es el caso de la publicidad que aparecía el 21 de diciembre de 1867 bajo el título "Preservativo contra el cólera" por el cual se recomendaba la compra y consumición de "cigarrillos ricos a muy moderado precio"; quien recomendaba el tabaco para evadir el cólera era Gustavo Follín (Eco..., 21 dic. 1867). Es posible que este negocio no haya sido demasiado conocido, pues trataba de ubicar a quien quería adquirir los productos: "Frente a la casa del Sr. Rudesindo Ibazeta." 
En momentos en que se acrecentaban las muertes por la epidemia, el 24 de diciembre (ver Gráfico 1), la droguería del Águila Dorada, posiblemente como una forma de marketing, daba gratis azufre preparado para fumigaciones a cualquier hora del día y hasta las 9 de la noche.

\section{Gráfico}

Total de muertes en la ciudad de Córdoba entre el 16 de Diciembre de 1867 y el 21 de Enero de 1868

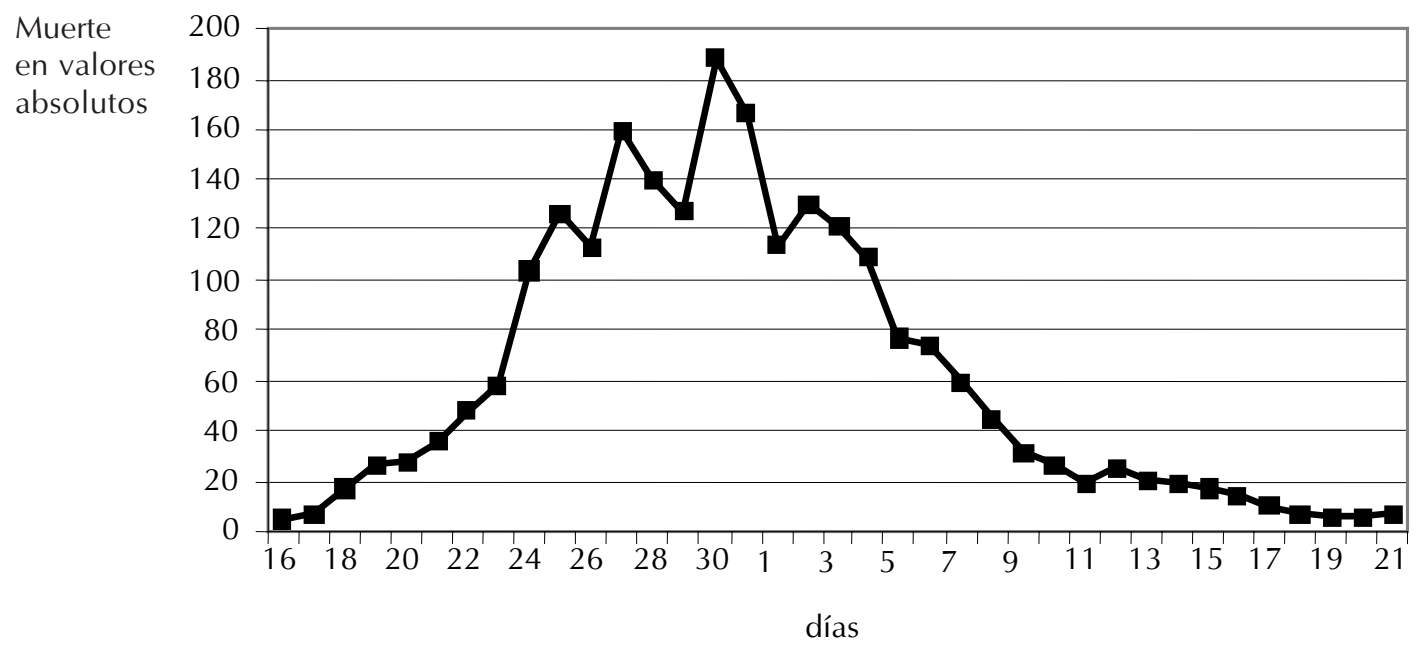

Fuente: Elaboración propia sobre la base de datos de Garzón Maceda, Félix, La medicina en Córdoba, Talleres Gráficos Rodríguez Giles, Buenos Aires, 1917, p.678.

Otra botica, esta vez la de la Avenida, publicitaba la venta de cloruro de cal y en el anuncio exponía los usos que podría darse a ese tipo de productos: "Se usa para regar piezas y patios, sirve para purificar el aire y muy usado, al igual que agua de Zeits, extracto de canela, extracto de menta, peperina" (Eco..., 25 dic. 1867).

En el Eco de Córdoba, durante todo el proceso de la epidemia, se repitieron constantemente todos los avisos antes expuestos. Pero no sólo se trataba de la oferta de productos anticoléricos para ser consumidos por la población, también el cólera generaba oferta y demanda de habitaciones en las afueras de Córdoba y es posible que el alquiler de éstas haya sido bastante caro, pues los únicos que salían de la ciudad eran los sectores más acaudalados. De esta forma, ciertos sectores también encontraban nichos económicos que el cólera permitía explotar, como por ejemplo piezas para guarecerse de la epidemia hasta que pasara. En este caso también la publicidad aparecía vinculada a un preservativo contra el cólera: "El que necesite algunas piezas en el campo, hacia la sierra, las hay en Santiago, hacienda de Don Marcos Arredondo, el que se interese puede verse con su dueño" (Eco..., 19 dic. 1867). 
Si bien el cólera generaba el desarrollo de la oferta de ciertos productos, también era utilizado, nuevamente, para llamar la atención de los lectores. Los avisos ponían el acento, en su título sobre la epidemia de cólera pero en su contenido aquel desaparecía o tenía algún otro tipo de significación. Uno de los casos más significativo es la propaganda aparecida el 18 de diciembre, momentos en los que ya la epidemia se había desatado. Con el título “El cólera iiiiiAtención!!!!!!!", el contenido estaba completamente alejado de la enfermedad: "En la panadería de Don José de Igarsabal se vende pan caliente superior desde las 8 y $1 / 2$ de la noche en adelante. También se hallará galleta América mejor que la que se conoce hasta hoy" (Eco..., 18 dic. 1867).

El 24 de diciembre, aparecía otro tipo de publicidad que utilizaba el cólera para otros fines. Esta vez el título era "Remedio del cólera". Sin embargo, el contenido del aviso estaba destinado a convencer a quien "hubiese hallado una cartera" para que la devolviera y la forma de convencer a quien la tuviera era la siguiente: "y la entregare a esta redacción quedará garantido contra el cólera y recibirá una generosa gratificación" (Eco..., 24 dic. 1867). El aviso no dejaba de tener una importante cuota de inteligencia: por un lado llamaba la atención al lector, pero por otro lado prometía, utilizando el horror y el miedo a la enfermedad, la preservación de la dolencia a partir de la devolución del objeto perdido.

Desde el 25 de diciembre hasta el 17 de enero, es decir los días en que más incidencia tuvo la enfermedad sobre la mortalidad de la población, según el Gráfico 1, no pudimos obtener información mediante periódicos. En realidad, es imposible saber si éstos fueron publicados y se perdieron o nunca fueron editados. Sin embargo, en un periódico del 5 de enero encontramos avisos del mismo tipo de los que se expusieron a lo largo del trabajo.

El 17 de enero de 1868, cuando la epidemia se encontraba en retirada, se pueden leer en el Eco de Córdoba publicidades de nuevos productos como el que ofrecía la Botica del Águila. Este aviso aparecía con el siguiente título: "Remedio eficaz y garantido contra el cólera inventado por el dr. Rubine de Nápoles". En este caso se trataba de la administración de cuatro gotas de tintura saturada de alcanfor cada cinco minutos, que en casos graves podría aumentarse la dosis entre 15 y 20 gotas (Eco..., 17 ene. 1868). Lo interesante de este producto era el marketing que llevaba su publicidad:

Este remedio ha sido preparado con exquisito arreglo a las prescripciones del Dr. Rubine y con vista de los diarios de Londres que contienen una relación del doctor firmado por el gobernador de Nápoles y los empleados más caracterizados ... Esa relación afirmaba que de 592 casos de cólera asiático, muchos de los cuales eran extremos, todos se salvaron. (Eco... 17 ene. 1868) 
${ }^{4}$ Recordemos que la huida de las ciudades era una estrategia de los sectores altos de la sociedad.

${ }^{5}$ A.A.C, Instituto de Estudios Americanistas $(08273$ Rollo 26), 13 ene. 1868 .

6 A.A.C, Instituto de Estudios Americanistas $(08273$ Rollo 26), 13 ene. 1868 .
La poción se vendía en la Botica del Águila. Esta misma botica publicitaba otro método, el del Dr. Alber, en este caso se trataba de gotas de una poción desconocida y era también para curar la enfermedad. En este caso se utilizaba en complemento con té de manzanilla y botellas de agua caliente para revertir los síntomas de la enfermedad (Eco..., 19 ene. 1868).

Otro artículo era publicitado por el Eco de Córdoba, el 19 de enero, ofrecido por la casa Senestrari. Se trataba de un licor higiénico o bien curativo anticolérico. En este caso, el marketing estaba dado por la cantidad de usos que podría darse al producto y esto se acentuaba porque "es el agente curativo más diligente y más eficaz contra el cólera". Según este aviso, si se tomaba al principio del flagelo "queda reducido a un malestar pasajero" y por lo tanto el paciente quedaba exento de todo tratamiento (Eco..., 20 ene. 1868).

A partir del desarrollo de la epidemia, la oferta de productos ha ido cambiando con la aparición de publicidad que estaba dirigida a la cura de la enfermedad mediante productos que estaban respaldados por doctores, si bien desconocidos para Córdoba, que habían tenido 'éxito' en otros lugares donde había aparecido la epidemia y eran ofrecidos especialmente por las boticas de la ciudad. Si bien la aparición de estos productos no anulaba las anteriores, la publicidad tendía a poner el énfasis en la cura y no en la prevención de la enfermedad.

En una carta que enviaba C. R. Lozano a un hermano el 13 enero de 1868 desde Río Ceballos, donde había huido con su familia, se pueden apreciar los productos que se consumían en hogares con altos ingresos": "Hay medicamentos. Escencia de menta, tintura de (sic). Vendría bien un poco más de éter. Licor anticolérico, tintura anticolérica. Gotas aniticoléricas del Dr. Frances instrucción de Wever. Hay lo necesario para cataplasmas, que requerimos sin embargo un poco de muestra".$^{5}$

En la correspondencia se exponen los principales paliativos para combatir al cólera y que no se diferenciaban de los productos que ofrecían especialmente las farmacias cordobesas. Hay que tener en cuenta que en este caso se trataba de un momento en el que la epidemia se había desatado y por lo tanto el arsenal de la farmacopea estaba destinado a curar la enfermedad y no para evitar el cólera. A tal punto que, a renglón seguido, quien escribía la carta solicitaba a su hermano instrucciones para el caso de que el enfermo superara los vómitos y diarreas: "Sucede que desaparecido el vómito, diarrea y calambres, tiene el enfermo fiebre. En este estado álgido o como sea de la enfermedad, no sabemos absolutamente lo que deba hacerse, ni nada de lo que deba darse al enfermo. Consulta sobre todo esto". ${ }^{6} \mathrm{El}$ consumo de estos productos estaba, en este caso, destinado a la cura y no a la prevención de la enfermedad. Queda por saber las formas como se administraban y los precios con los que se podía acceder. 


\section{A modo de conclusión}

En términos generales, se pueden apreciar dos momentos en la oferta de productos como consecuencia del desarrollo del cólera entre principios de 1867 y enero y febrero de 1868. En un primer momento, cuando aún no se había desarrollado la epidemia y ésta constituía una amenaza, los productos, especialmente de carácter suntuario, estaban dirigidos a prevenir el cólera mediante su consumición. Se trataba, en la mayoría de los casos, de licores de carácter aromático, chocolates y cigarrillos que acordes a las percepciones del momento preservaban del cólera mediante el alejamiento de los olores nauseabundos o mediante la facilitación de la digestión. Este tipo de ofertas se pueden apreciar desde que el cólera se desata en Rosario, en los primeros meses de 1867, hasta que la enfermedad representa una amenaza para la ciudad, a fines del año 1867, y cuando éste era ya una realidad ineludible para la población. En esta etapa se aprecia una multitud de productos ofertados por todo tipo de establecimientos como almacenes de ramos generales, confiterías, boticas en los cuales se alcanza a percibir cierta competencia.

En el segundo momento, a principios de enero de 1868, cuando la epidemia reducía su incidencia, comienza a aparecer una serie de productos destinados, ya no a prevenir, sino a curar la enfermedad, esta vez se trataba de productos cuyos métodos de cura eran respaldados por nombres de doctores, suponemos, desconocidos para la población y que justificaban su consumición a partir del 'éxito' obtenido en otros lugares donde se había desarrollado el cólera y en el respaldo del título de quien los realizaba. En este caso eran las boticas las que ofrecían los productos mientras los almacenes y confiterías conservaban la publicidad de los licores y cigarrillos.

Pero el cólera no sólo generaba la venta de este tipo de artículos, también había anuncios sobre el ofrecimiento de habitaciones a quienes quisieran huir de la ciudad. Según parece, si bien había ofrecimientos, la huida se llevaba a cabo, en muchos casos, sin planificación alguna. En ese sentido se pronunciaba el protomédico de la provincia que advertía a los vecinos de Córdoba sobre la salida precipitada de la ciudad y sus consecuencias por las condiciones higiénicas que los hacían víctimas de la epidemia, como habría sucedido en algunos casos (Eco..., 29 dic. 1867).

Pero también el cólera fue utilizado para dirigir la atención hacia otras cuestiones como la publicidad de productos que nada tenían que ver con el desarrollo de la enfermedad como la venta de pan, la venta de una propiedad, la devolución de joyas o de carteras que se habrían perdido.

Se puede apreciar por lo dicho hasta el momento que el cólera no sólo generó la acción por parte del Estado y la medicina frente a 
la enfermedad, sino que también se constituyó en un elemento de desarrollo de transacciones de todo tipo a fin de generar la salvación frente a la epidemia como en muchos casos artículos suntuarios pero también pócimas hechas adrede para la cura de la enfermedad, generando competencias dentro del mercado.

Este es un primer paso a fin de entender el desarrollo del consumo a lo largo de las epidemias de cólera, especialmente cuando aún la medicina académica no había conseguido el monopolio de la atención de la salud. Sin embargo, queda aún por investigar cuál fue el consumo diferencial entre distintos sectores sociales, qué prácticas fueron la más comunes, en qué coincidieron y en qué se diferenciaron.

\section{BIBLIOGRAFÍA}

Arcondo, Aníbal 1997

Bardet, Jean-Pierre et al.

1988

Betancor Gómez,

Maria Josefa; Marset

Campos, Pedro

1994

Bourdelais, Patrice;

Raulot, Jean-Yves 1987

Carbonetti, Adrián 2003

Cipolla, Carlo 1993

Eco... 6 abr. 1867

Eco... 14 abr. 1867

Eco... 18 abr. 1867

Eco... 23 abr. 1867

Eco... 30 abr. 1867

Eco... 5 jul. 1867

Eco... 12 dic. 1867

Eco... 13 dic. 1867
Las epidemias de cólera en Córdoba (Argentina) durante el siglo XIX. Rosário: Escuela de Historia/Universidad Nacional de Rosario. Separata de: 17 Anuario, segunda epoca (1995-1996).

Peurs et terreurs face a la contagion: choléra, tuberculose et syphilis, XIX ${ }^{\mathrm{e}}$ et $\mathrm{XX}$ siècles. Paris: Fayard.

La epidemia de cólera de 1851 en Las Palmas de Gran Canaria. In: Congreso Internacional de Historia de la Medicina, 33., GranadaSevilla, 1992. Actas... Sevilla: Sociedad Española de Historia de la Medicina. p.497-512.

Un peur bleue: historie du cholera en France 1832-1854.

Paris: Libris.

Visiones médicas acerca del cólera a mediados del siglo XIX en Argentina. In: Lorenzano, Julio Cezar (Ed.). Historia de la Ciencia en Argentina, 1. Buenos Aires: Editorial de la Universidad Nacional Tres de Febrero. p.147-159.

Contra un enemigo mortal e invisible. Barcelona: Editorial Crítica.

Eco de Córdoba, Córdoba.

Eco de Córdoba, Córdoba.

Eco de Córdoba, Córdoba.

Eco de Córdoba, Córdoba.

Eco de Córdoba, Córdoba.

Eco de Córdoba, Córdoba.

Eco de Córdoba, Córdoba.

Eco de Córdoba, Córdoba. 
Eco..

18 dic. 1867

Eco..

19 dic. 1867

Eco...

21 dic. 1867

Eco...

24 dic. 1867

Eco...

25 dic. 1867

Eco...

29 dic. 1867

Eco...

17 ene. 1868

Eco...

19 ene. 1868

Fernández Sanz,

Juan José

1991

Goldman, Noemí

1990

Gómez Días, Donato 1993

Mc Neill, William 1984

McKeown, Thomas 1990

Nadal, Jordi

1992

Penna, José

1897

Prieto, Agustina

1996

Ruggiero, Romano:

Tenenti, Alberto

1970

Sournia, Jean Charles 1997

Tancredi, Elda; Tuis, Claudio

2001
Eco de Córdoba, Córdoba.

Eco de Córdoba, Córdoba.

Eco de Córdoba, Córdoba.

Eco de Córdoba, Córdoba.

Eco de Córdoba, Córdoba.

Eco de Córdoba, Córdoba.

Eco de Córdoba, Córdoba.

Eco de Córdoba, Córdoba.

Incidencia en la población del país valenciano del cólera de 1885.

In: Bernabeu Mestre, Josep (Coord.). El papel de la mortalidad en la evolución de la población valenciana. Alicante: Instituto de Cultura Juan Gil Albert. p.81-88.

El levantamiento de montoneras contra gringos y masones en Tucumán 1887: tradición oral y cultura popular. Boletín del Instituto de Historia Argentina y Americana, Buenos Aires, n.2, serie 3, p.47-74.

Bajo el signo del cólera y otros temas sobre mortalidad, higiene y salubridad de la vida económica almeriense, 1348-1910. Almería: Instituto de Estadísticas de Andalucía.

Plagas y pueblos.

Madrid: Siglo XXI.

Los orígenes de las enfermedades humanas.

Barcelona: Editorial Crítica.

Bautismos, desposorios y entierros: estudios de historia demográfica. Barcelona: Editorial Ariel.

El cólera en la República Argentina. Buenos Aires: Litográfica y Encuadernación de Jacobo Peuser.

Rosario: epidemias, higiene e higienistas en la segunda mitad del siglo XIX. In: Lobato, Mirta (Comp.). Política, médicos y enfermedades: lecturas de historia de la salud. Mar del Plata: Biblos; Universidad de Mar del Plata.

Los fundamentos del mundo moderno: Edad Media tardía, Reforma y Renacimiento. México: Siglo XXI.

O homem e a doença. In: Le Goff, Jacques (Org.).

As doenças têm história. Lisboa: Terramar. p.359-361

La epidemia de cólera de 1867-1868 y su impacto sobre la población de los partidos de Luján y Navarro: reconstruyendo la articulación entre ambiente-agua-enfermedad en la región pampeana. In: Jornadas Argentinas de Estudios de Población, 5., 1999, Luján. V Jornadas... Luján: Asociación de Estudios de Población de la Argentina; Unversidad Nacional de Luján. p.381-396.

Recibido para publicación en agosto de 2006.

Aprobado para publicación en octubre de 2006. 